\title{
Effectiveness of Constructivist Teaching Method on Students' Mathematic Academic Achievement
}

\author{
Fereshte Heydari Aydisheh ${ }^{1}$ \\ Hassan Gharibi2

\begin{abstract}
M.A. Student in Curriculum Studies, Islamic Azad University, Tabriz Branch.Email: fereshteheydari97@gmail.com Assistant Professor, Department of Psychology, Payame Noor University (Corresponding Author). Email: hgharibi33@gmail.com
\end{abstract}

\author{
Doi:10.5901/mjss.2015.v6n6s2p572
}

\section{Abstract}

The present study was aimed at investigating the effect of constructivist teaching on students' academic achievement in mathematics. The study was an applied research with a quasi-experimental design and a control group. The statistical population consisted of 364 third grade girl students from high schools of Miandoab, Iran. To select the study sample, cluster random sampling was employed. In so doing, from among 6 schools with a total of 14 classes, one school was selected by a multistage method. Then, two classes of the selected school were randomly chosen; one as the experimental group and the other one as the control group. Instruments included a researcher-made questionnaire that was designed based on principles of academic achievement of Bloom's cognitive domain. The results indicated that constructivist teaching affects knowledge, understanding, application, analysis, combination, and evaluation. Based on the results of the study, it can be concluded that constructivist teaching can help with students' academic achievement.

Keywords: constructivism theory, academic achievement, mathematic.

\section{Introduction}

In Iran's educational system, it has been for a long time that teachers have been utilizing traditional methods especially lecturing in order to encourage students to memorize and repeat scientific concepts. A variety of causes prevents social development and academic achievement in students, among which one can refer to inactive teaching (Keramati, 2005). Teaching is aimed at enhancing learning capacities and benefiting from proper dimensions of intelligence. Good teaching leads to good learning. Students who learn well develop good approaches of learning and acquiring knowledge. Teaching models help students develop such approaches in themselves. Such models assist students' development and consider them as individuals with ability to enhance logical thinking and behavior and create social skills and commitment (Behrangi \& Aghayari, 2004). One of the major properties of constructivist teaching is the teacher's and learner's roles, in this approach teacher is the facilitator of learning and plays the main role in learning process (Vavrus, 2009: 76).

\section{Literature Review}

Santrock (2004, ac cited by Seif, 2008) believes that constructivism is an approach to learning that puts emphasis on learner's activeness in establishing knowledge and comprehension. In a constructivist class, mathematics teacher provides the students with real and meaningful problems and encourages them to present various solutions, seek help from classmates, and introduce the best solution. Such a teacher is not a knowledge transmitter or distributor but rather is a guide, facilitator, and assistant to the students. A constructivist teacher should notice that learners should be faced with any concept through a variety of methods and situations with different objectives and experiences so that they can perform better in producing and transmitting the constructed knowledge. Constructivists prioritize formative evaluation over other methods (Karami, 2009: 81). It can be stated that as paying attention to constructivist approaches shifts, class evaluation is increasingly highlighted as a serious means of learning processes (Seif, 2006: 65). Constructivist principles are based on awareness about learning, and it is mainly concerned with the fact that knowledge is not transmitted to the learners, but rather this is the learners that construct the knowledge for themselves. Constructivist learning is aninternal dynamic process whereby the learners actively "construct knowledge" by linking new information with what they have previously learned (Hosseini, 2009: 30). Contemporary theories that have affected learning and educational systems can be classified into two major groups: conditional theory (behaviorism) and cognitive theory (Sha'bani, 2007). Numerous 
schools of learning such as behaviorism, cognitivism, etc. have interpreted and explained learning differently. Teaching is one of the concepts that is directly related to learning. Many definitions have been proposed for teaching, and it seems that most of them have introduced teaching as an interpersonal process and activity in which teachers and learners have mutual effects on each other. Anderson and Burns have defined teaching as, "an interpersonal practice that includes different forms of verbal communication aimed at assisting learners or changing their behavior" (Elliot et al, 1996). Therefore, formative evaluation is uniquely important. In other words, constructivists instead of measuring the level of students' good or bad performance evaluate the extent and kind of help the students need to succeed (Nili, 2014: 21).

Cey (2001) believes that as unicorns do not exists, "constructivist mathematics" has no existence; however, there are some theories of learning that are classified as constructivist and can be related to basic standards of mathematics. There are at least two definitions for constructivism that clarify mathematics teaching: radical constructivism and social constructivism. A type of social constructivism that is specifically used for mathematics teaching claims that mathematics should be taught with an emphasis on problem solving, in which interaction should first happens between teachers and students and then among the students, and students should be encouraged to create their own strategies in dealing with problem solving situations (Stiff, 2001). In traditional methods of education, evaluation is the final step and is conducted to make decision about student's promotion to higher educational levels. However, nowadays evaluation is an inevitable section of teaching-learning process, and instead of classifying the students it focuses on guiding their learning (Sharifi, 2004, as cited by Rezaeei \& Seif, 2006). Qualitative-descriptive model of evaluation as the complete version of continuous evaluation is intended to institutionalize its different method within the body of the educational system (Hassani \& Kazemi, 2003, as cited by Hassani \& Ahmadi, 2007). This phenomenon can be explained from at least to related perspectives: one is the new approaches in learning psychology like cognitivism and constructivism, and the other one is the revolution of educational reforms and change of curriculum and international comparisons in different courses and need for enhancing educational standards (Seif, 2003; Black \& Williams, 1998, as cited by Rezaeei \& Seif, 2006: 13). Teaching model helps students develop such approaches in themselves. These approaches helps with development of the students as individuals with ability to increase rational thinking and behavior and create social skills and commitments (Behrangi \& Aghayari, 2004). Academic achievement refers to the learners' success in academic tasks that can be evaluated through testing (Hossini Nasab \& Ali Aghdam, 1996). Both teaching and learning include extensive and detailed activities that should be paid close attention (Alagheband, 2010: 186). Understanding this fact in recent three decades has resulted in several fundamental changes (with different significance) in different countries (with different speed and quality). These changes can be classified in three general groups: 1) Student- and process-centered collaborative active learning, 2) Utilization of new information technology during teaching and learning, and 3) Focus on teaching global training fields like economics, environment, culture, politics, and technology (Kiyamanesh, 2004). Advent of constructivist theory as an influencing theory in education dates back to the second half of the $20^{\text {th }}$ century (Niaz, 2008). In fact, origins of constructivist theory are retrieved from ideas of Dewey, Piaget, and Vygotsky. Here, teacher is introduced as a guide and someone who authorizes the students and gives them motivation and ability to enhance their learning and develop their thinking by providing an open environment for questioning and arguable opposition to other views (Aviram, 2000). In this perspective, learning as knowledge transmission that was the core of traditional education is diminishing and approaching toward construction of active and personal knowledge, skills, and ability development (Hrinkton \& Aliver, 2000).

Keramati (2003) investigated the effect of collaborative learning on development of social growth and academic progress of students' mathematics and concluded that the scores of social skills among boy students increased more than those of girl students, and that most students, teachers, and educational guides were satisfied with the proposed model (Keramati, 2003). Pakizeh (1997) investigated the effects of collaborative learning on university students' selfconcept. The results indicated that there was no significant difference between the collaborative learning group and traditional group in regard with their self-concept. Lak Dizeji et al (2005) compared the effects of lecture and discussion methods on nursing students' learning. The results of that study indicated that there was a significant difference between the two groups (i.e. lecture group and discussion group) in terms of their learning increase. Sharan and Slavin indicated that collaborative learning had a remarkable effect on students' academic achievement and interpersonal skills while competitive and individual methods had no positive significant effect (Kohen, 1994). Ervin (2001) carried out a study in elementary schools of Pennsylvania, the US and concluded that collaborative model of learning had a significant effect on students' learning enhancement regardless of their ethnic and economic status (cited by Fallah, 2008). Anoyobazi (2007) believes that students that are involved with collaborative learning achieve higher academic achievement and responsibility taking compared to students of individual learning models (Mehdizadeh, 2013). So the purpose of this study was investigate the effectiveness of constructivist teaching method on students' mathematic academic achievement(learning the knowledge, learning the concepts, learning the application, learning the analysis, learning the 
synthesis, learning the evaluation ). Based on the main question of the present study (Does constructive teaching of mathematics influence students' academic achievement?) following hypotheses are proposed.

1. Constructivist teaching is effective in academic achievement of high school third grade mathematics (geometry 2) of math major.

2. Constructivist teaching is effective in learning the knowledge of high school third grade mathematics (geometry 2) of math major.

3. Constructivist teaching is effective in learning the concepts of high school third grade mathematics (geometry 2) of math major.

4. Constructivist teaching is effective in learning the application of high school third grade mathematics (geometry 2) of math major.

5. Constructivist teaching is effective in learning the analysis of high school third grade mathematics (geometry 2) of math major.

6. Constructivist teaching is effective in learning the synthesis of high school third grade mathematics (geometry 2) of math major.

7. Constructivist teaching is effective in learning the evaluation of high school third grade mathematics (geometry 2) of math major.

\section{Method}

The present study was an applied research with a quasi-experimental design and a control group. The statistical population included 364 girl students who were studying in 6 high schools in Miandoab. This methodology was chosen because the purpose of the study. The purpose of this study was investigation the effectiveness of constructivist teaching on students' academic achievement in mathematics. So the best method was experimental with the control group for this. Since this method to more precisely control other variables and control their effects. The study sample consisted of 2 classes of 1 school that were selected through a cluster random multistage sampling method from among 6 schools (14 classes). One of the classes was selected as the experimental group (constructivist teaching, $n=35$ ) and the other one as the control group (traditional teaching, $n=35$ ). Data collection was carried out through a researcher-made questionnaire of academic achievement that included 6 criteria and 30 questions. The questionnaire contained 30 questions and 6 criteria (knowledge learning, concept learning, applied learning, analysis learning, synthesis learning, and evaluation learning) each was assigned 5 questions. To check the reliability of the questionnaire, Cronbach's Alpha was employed for the whole questionnaire using SPSS. In so doing, before the study the questionnaire was administered in one of the third grade classes, and its total reliability was calculated as 0.83 ; it was 0.74 for knowledge and concepts of mathematics, 0.75 for problem solving, and for academic achievement criteria like knowledge learning it was 0.80 , applied learning 0.73 , analysis learning 0.84 , synthesis learning 0.81 , and evaluation learning 0.79 . The questionnaire's face validity (acceptability of the questionnaire in terms of its format and appearance) and content validity (the content of the questions according to the study objectives and hypotheses) were confirmed by expert professors. The procedure of the study included conducting a pretest (in order to specify the students' current academic status in mathematics in both groups) of previously taught topics and a posttest of the topics that were taught during the experiment. In order to make sure that the selected students were not significantly different before the study, an exam from the previously taught materials was given. After it was assured that the studentshad not gained significantly different scores on the test, they were randomly divided into two groups of experimental and control. The experimental group was taught by constructivist method for 10 session while the control group was presented the same materials by traditional method. To analyze the collected data, descriptive statistics (including mean, standard deviation, and distribution tables and diagrams) and inferential statistics (independent samples t-test) were utilized.

\section{Specifications and Procedure of Constructivist Teaching}

Student's role:Constructivist classes usually have an atmosphere like that of training workshops where students learn from and teach one another. They accept collaboration as a principle in learning. In this collaborative approach, the teacher's role is to set a framework for students' learning and organize a discovery period in which students have direct relationship with materials and tools, and they learn how to learn. The teacher's role is that of a facilitator who intends to create the "oh moment" which is the time when the student says "I understood".

Teacher's Role:In constructivist approach, being familiar the students' previous views and experiences, the teachers design situations in which the learners can reconstruct and expand their knowledge. The most important role 
that the teacher takes is to facilitate the process of knowledge construction. Those who can conduct the following activities easily can help students with knowledge construction.

1. Presenter: The teacher is a presenter, not a lecturer. A teacher is someone who explains the issues, presents models, and provides the collaborative groups with different activities.

2. Observer: The teacher identifies the students' beliefs in formal and informal activities, interacts with them appropriately, and gives them special learning authorities.

3. Questioners and presenter of problems: The teachers guides the students toward idealization, encourage them to test their ideas, and praises conceptualization.

4. Environment organizer: Being aware of the students' perspectives, the teacher prepares the environment for the learners to experience things.

5. Coordinator of public relations: The teacher is someone who encourages collaboration in order to develop and enhance human relations and tolerance of different views.

6. Documentation of learning: The teacher measures the effect of the provided exercises on students and examines the created expectations.

7. Theoretician: Beside his/her activities, the teacher helps the learners connect between two or more thoughts and ideas and create a meaningful method.

Procedures of Conducting Constructivist Teaching: The target procedure included exploration, explanation, expansion, and evaluation.

1. Exploration:In constructivist method, exploration means that there are some ways to construct knowledge. Employing all their senses, the learners attempt to construct a part of the knowledge during their exploration. Exploration through collaboration results in utmost benefit.

2. Explanation: In this stage, the teachers interact with the students so that they can understand the presented views and materials. In order to interact effectively, the teachers need to ask questions relevant and appropriate to previous ones. Another duty that the teachers should take is to help the learners form their thoughts and beliefs they have created through exploration and shared with others. In other words, learners should share their discoveries with others.

3. Expansion:In this phase, teachers assist students expand their mental and motor activities or skills. Here, the students are assisted to revise their views and correct their skills.

4. Evaluation:It is necessary to evaluate students' methodological discoveries, acquired skills, and qualification in order to know changes happened in thoughts and mastery over skills and to provide the learners with related feedback. In this phase, it is better to utilize thought-provoking questions in order to evaluate the learners' knowledge uptake and production. Moreover, self-assessment should also be encouraged.

\subsection{Learning content: Third Grade Geometry Book 2, Math Major}

Chapter 1: Reasoning in Geometry (1.1. Inductive Reasoning, 1.2. Deductive Reasoning, 1.3. Counterexample, 1.4. Conditional Theorems, 1.5. Opposite Theorem, 1.6. Two Conditional Theorem, 1.7. Indirect Proof or Reductio ad absurdum, 1.8. Geometrical Position, 1.9. Drawing with Ruler or Compass).

Chapter 2: Circle (2.1. Circle, Central Angle, Chord, and Tangent, 2.2. Inscribed Angle, 2.3. TangentialAngle, 2.4. Intercepted Arc, 2.5. Angle between Two Chords. These topics were taught in 10 sessions. In so doing, the experimental group was taught by constructivist method and the control group by traditional method.

\section{Results}

Hypothesis 1: Constructivist teaching is effective in academic achievement of high school third grade Mathematics (Geometry 2) of math major.

Table 1. Independent t-test for hypothesis 1

\begin{tabular}{lcccc}
\hline Test Value=3 & & & & \\
\hline Variable & Mean & T & Sig̃. & MD \\
\hline Academic Achievement & 18.5714 & 34.314 & 0.001 & 18.57143 \\
\hline
\end{tabular}

According to the results of t-test and the significance level, it was concluded that constructivist teaching is effective in 
academic achievement of high school third grade Mathematics course (Geometry 2) of math major.

Hypothesis 2: Constructivist teaching is effective in knowledge learning of high school third grade Mathematics (Geometry 2) of math major.

Table 2. Independent t-test for hypothesis 2

\begin{tabular}{lcccc}
\hline Test Value=3 & & & & \\
\hline Variable & Mean & T & Sig. & MD \\
\hline Knowledge Learning & 17.8000 & 32.562 & 0.001 & 17.8000 \\
\hline
\end{tabular}

According to the results presented in Table 2, it can be concluded that constructivist teaching is effective in knowledge learning of high school third grade Mathematics course (Geometry 2) of math major.

Hypothesis 3: Constructivist teaching is effective in concept learning of high school third grade Mathematics (Geometry 2) of math major.

Table 3. Independent t-test for hypothesis 3

\begin{tabular}{lcccc}
\hline Test Value $=3$ & & & & \\
\hline Variable & Mean & T & Sig. & MD \\
\hline Concept Learning & 16.9143 & 31.891 & 0.001 & 19.91429 \\
\hline
\end{tabular}

The results of t-test indicated that constructivist teaching is effective in concept learning of high school third grade Mathematics course (Geometry 2) of math major.

Hypothesis 4: Constructivist teaching is effective in applied learning of high school third grade Mathematics (Geometry 2) of math major.

Table 4. Independent t-test for hypothesis 4

\begin{tabular}{lcccc}
\hline Test Value $=3$ & & & & \\
\hline Variable & Mean & T & Sig. & MD \\
\hline Applied Learning & 17.74286 & 31.876 & 0.001 & 17.742875 \\
\hline
\end{tabular}

The results presented in Table 4 indicated that constructivist teaching is effective in applied learning of high school third grade Mathematics course (Geometry 2) of math major.

Hypothesis 5: Constructivist teaching is effective in analysis learning of high school third grade Mathematics (Geometry 2) of math major.

Table 5. Independent t-test for hypothesis 5

\begin{tabular}{lcccc}
\hline Test Value=3 & & & & \\
\hline Variable & Mean & T & Sig. & MD \\
\hline Analysis Learning & 18.4571 & 32.212 & 0.004 & 18.45714 \\
\hline
\end{tabular}

The results presented in Table 5 above showed that constructivist teaching is effective in analysis learning of high school third grade Mathematics course (Geometry 2) of math major.

Hypothesis 6: Constructivist teaching is effective in synthesis learning of high school third grade Mathematics (Geometry 2) of math major.

Table 6. Independent t-test for hypothesis 6

\begin{tabular}{lcccc}
\hline Test Value=3 & & & & \\
\hline Variable & Mean & T & Sig̃. & MD \\
\hline Synthesis Learning & 17.6857 & 33.814 & 0.001 & 17.68571 \\
\hline
\end{tabular}


The results of the t-test indicated that constructivist teaching is effective in synthesis learning of high school third grade Mathematics course (Geometry 2) of math major.

Hypothesis 7: Constructivist teaching is effective in evaluation learning of high school third grade Mathematics (Geometry 2) of math major.

Table 7. Independent t-test for hypothesis 7

\begin{tabular}{lcccc}
\hline Test Value $=3$ & & & & \\
\hline Variable & Mean & T & Sig. & MD \\
\hline Evaluation Learning & 14.1714 & 35.562 & 0.001 & 14.17143 \\
\hline
\end{tabular}

The results showed that constructivist teaching is effective in evaluation learning of high school third grade Mathematics course (Geometry 2) of math major.

\section{Freedman Test to Specify the Priority of Academic Achievement Criteria}

In order to determine priority and importance of academic achievement criteria, the means of the component criteria were calculated for each criterion and compared to one another through Freedman test. Their mean ranking is presented in Table 8.

Table 8. Freedman test for academic achievement criteria

\begin{tabular}{|c|c|l|c|}
\hline \multicolumn{2}{|c|}{ Freedman Test } & Criterion & Mean Rank \\
\hline $\mathrm{N}$. & 35 & Knowledge Learning & 6.77 \\
\hline $\mathrm{X}^{2}$ & 2061.664 & Concept Learning & 6.05 \\
\hline $\mathrm{df}$ & 9 & Applied Learning & 6.33 \\
\hline Sig. & 0.0000 & Analysis Learning & 6.06 \\
\hline \multirow{2}{*}{} & Synthesis Learning & 2.94 \\
\cline { 2 - 4 } & Evaluation Learning & 1.00 \\
\cline { 2 - 4 }
\end{tabular}

According to Table 8, among the academic achievement criteria, knowledge learning criterion with a mean rank of 6.77 had priority and more importance than other criteria, following by applied learning with mean rank of 6.33 , analysis learning 6.06, and concept learning 6.05.

\section{Discussion and Conclusion}

The present study was conducted to investigate the effect of constructivist teaching on academic achievement of high school third grade Mathematics course (Geometry 2) of math major. Academic achievement refers to the learners' success in academic affairs that can be evaluated using related tests (Behrangi \& Aghayari, 2004). The results for the first hypothesis indicated that constructivist teaching is effective in academic achievement of high school third grade Mathematics course (Geometry 2) of math major. The results of the present study are in line with the theory proposed by Sharifi (2004, cited in Rezaeei \& Seif, 2005). This theory states that evaluation is an inseparable part of teaching-learning process, which instead of classifying the students guide their learning. Stiff (2002) also believes that radical constructivism is a type of social constructivism that is specifically used for math students. He claims that mathematics should be taught with an emphasis on problem solving. Behrangi and Aghayari (2004) believe that teaching is aimed at enhancing learning capacity and benefiting from appropriate intelligence dimensions. Good teaching brings about good learning. Students that are equipped with good learning strategies learn well. Santrock (2004) states that constructivism is a learning approach that emphasizes the learner's activeness in constructing knowledge and understanding. These findings are in agreement with those of the study carried out by Keramati (2003), Lak Dizaji et al (2005), and Mortazavi et al (2005). According to the results reported by Keyvanfar, if active methods of teachingare appropriately utilized in class, theyresult in students' science grades. These methods can help the students internalize the learning materials so that they can use their discoveries in their new social success. The results of the second hypothesis indicated that constructivist teaching is effective in knowledge learning of high school third grade Mathematics course (Geometry 2) of math major. This finding is in line with that of Lak Dizaji et al (2005), Aliabadi and KArimi (2008), and Anoyobazi (2002). 
The results for the third hypothesis showed that constructivist teaching is effective in concept learning of high school third grade Mathematics course (Geometry 2) of math major. Hosseini (2009) believes that constructivist teaching is an internal dynamic process in which learners "construct knowledge" actively and by connecting new information with what they have previously learned. Vavrus (2009) introduced the teacher's and the learner's roles as the main specifications of constructivist teaching. In this method, teacher as a facilitator of learning plays the main role. The results for the fourth hypothesis indicated that constructivist teaching is effective in applied learning of high school third grade Mathematics course (Geometry 2) of math major. And the results for the fifth hypothesis showed that that constructivist teaching is effective in analysis learning of high school third grade Mathematics course (Geometry 2) of math major. These findings are in line with those reported by Anoyobazi (2002). Seif (2008) believes that constructivism is a learning approach that highlights the construction of knowledge and understanding. The results for the sixth hypothesis indicated that constructivist teaching is effective in synthesis learning of high school third grade Mathematics course (Geometry 2) of math major. And the results of the seventh hypothesis showed that constructivist teaching is effective in evaluation learning of high school third grade Mathematics course (Geometry 2) of math major. These findings are in agreement with those reported by Aliabadi and Karimi (2008) and Ervin (2001). In general, it should be noted that most conducted studies of constructivist teaching have been aimed at figuring out constructivist concepts between teachers or the effects of the view on teaching trend, students, and class. However, the present study was intended to analyze constructivist criteria; therefore, it cannot be directly compared with previous studies. Cey (2001)believes that learners should encounter every concept in a range of situations with different objectives and experiences so that knowledge transmission occurs more efficiently. Nili (2014) believes that constructivists instead of evaluating the students' performance as good or bad move toward the idea of how much help the students need to succeed. Learning in this method is obtained through the student's independent experience; therefore, special attention is devoted to the student's personal experience and activity. According to the importance of mathematics course and Iran's status in international evaluations, it is necessary to revolutionize teaching and learning methods of this course. Constructivist theory in one of the significant theories of teaching and learning mathematics and science courses. Based on the results of the present study, it can be stated that this method is one of the most important tools that is adaptable with modern sciences and current situations in creating better educational results especially in mathematics. Elliot et al (1996) defined teaching as an interpersonal practice that includes different forms of verbal communication aimed at assisting learners or changing their behavior. Total results indicated that constructivist teaching affects understanding, analysis, synthesis, and evaluation. Therefore, it can be stated that constructivist teaching can help with academic achievement. As the limitations of the study, one can refer to the point that the study was conducted on girl students; therefore, the results should be generalized for boy students and other grades with much caution. According to the findings of the study, it is suggested that constructivist teaching be investigated for boy schools, other grades and courses, and other academic skills. Participating students and all of those who helped us with the present study are warmly thanked.

\section{References}

Alagheband, A. (2010). Theoretical basics and principles of educational management. Ravan Publication: Tehran. (In Persian)

Anvydyazy(2002). Using Computer Assisted Instruction to Compare the Inventive Model and the Radical Constructivist Approach to Teaching Physics. Journal of Science Education and Technology.

Aviram, M. Dornfeld, L. Rosenblat, M. Volkova, N. Kaplan, M. Coleman, R. Hayek, T. Presser, D. and

Behrangi, M. \& Aghayari, T. (2004). Revolution caused by jigsaw collaborative teaching in the current traditional teaching situation. Educational Innovations Journal, 10(3). (In Persian)

Cey, T., (2001), Moving Toward Constructivist Classrooms, Retrieved December 19, 2009, from http://www.usask.ca/education/ coursework/802papers/ceyt/ceyt.htm

Elveyt(1996), Vygotskian theory and mathematics education: Resolving the conceptualprocedural dichotomy, European Journal of Psychology of Education

Fallah, N. (2008). The effect of traditional and collaborative teaching methods on pre-university students' academic achievement and attitude toward learning of theology in Tabriz in academic year of 2008-9. Unpublished M.A. Thesis, Islamic Azad University of Tabriz. (In Persian)

Fuhrman, B. (2000). Pomegranate juice consumption reduces oxidative stress, Am j clin Nutr. 71, 1062-76.

Hassani, M. \& Ahmadi, H. (2005) Modern model in academic evaluation: Descriptive evaluation, evaluation for better learning. Madreseh Publication: Tehran. (In Persian)

Hosseini Nasab, M. \& Ali Aghdam, N. (1996). Constructivist mathematics teaching. Journal of Curriculum Research, 5. (In Persian)

Hrinkton \& aliver(2000) Haptic's suitability to constructivist learning environment: aspects of teachers and teacher candidates. Social and Behavioral Sciences

Keramati, M. (2005). Investigating the effect of collaborative learning on development of social skills and academic achievement of math 
course among elementary $5^{\text {th }}$ grade students in Mashhad. Pazhuhesh Monthly, 3(8). (In Persian)

Kiyamanesh, A. (2004). Evaluation of the $3^{\text {rd }}$ phase of comprehensive and collaborative education plan (guidance $2^{\text {nd }}$ grade): Achievements and perspectives. Education Research Journal, 1\&2(19\&20). (In Persian)

kohen(1994). predictiong achievement in college -level foreign language courses .

Lak Dizaji, S., Razavi, N., Dawudi, A. \& Valizadeh, S. (2005). A comparison of the effect of lecture and discussion methods of teaching on nursing students' learning. The Journal of Education in Medicine, 14. (In Persian)

Mehdizadeh, M. (2001). The effect of information thechnology and communication on math learning. Information Technology and Communication in Education, 1. (In Persian)

Niaz .M (2008). Whither constructivism? A Chemistry Teachers' perspective. Teaching and Teacher Education.24: 400-416.

Nili, M. R. (2014). Analyzing the place of constructivism as a modern learning approach in elementary textbooks. The Journal of Curriculum, 40. (In Persian)

Pakizeh, A. (1997). Investigating the effect of collaborative learning on university students' academic performance and self-concept in Bushehr Islamic Azad University. Unpublishe M.A. Thesis, Education and Psychology Department, Allameh Tabatabaee University. (In Persian)

Rezaeei, A. \& Seif, A. A. (2006). The effect of descriptive evaluation on students' cognitive, mental, and psychological-motor characteristics. Educational Innovations Journal, 18. (In Persian)

Seif, A. A. (1994). Evaluating and measuring academic achievement. Agah Publication: Tehran. (In Persian)

Seif, A. A. (2008). Constructivist theory and its relationship with teaching methodology among high school teachers. SAMT Publication: Tehran. (In Persian)

Sharan, S. (1980). Cooperative learning in small groups Recent methods an effects on achievement, attitudes and ethnic relations, Review of Educational Research, 10, 241-271.

Sharifi, H. P. (1974). Evaluation and measurement in education and psychology. Khan-e Ferdous Publication: Tehran. (In Persian)

Slavin(1990). Learning to Teach in Higher Education. Londan: Outledge.

Slavin, R. E. (2006). Educational Psychology: Theory and Practice (8thed.). New York: Pearson.

Stiff, L. V., (2001). Constructivist Mathematics an Unicorns, NCTM News Bulletin, [online], Available: http://www.nctm.org/about/ content.aspx?id=1238.html.

Vavrus. F (2009). The Cultural Politics of Constructivist Pedagogies: Teacher Education Reform in the United Republic of Tanzania. International Journal of Educational Development. 29: 303-311

Wong J, Beglaryan H. Strategies for Hospitals to Improve Patient Safety: A Review of the Research. 2004 available from 